\title{
Analysis of Middle Aged and Elderly Women's Foot Shapes for Shoe Design
}

\author{
Ho-Sun Lim ${ }^{\dagger}$ \\ Dept. of Clothing \& Textiles, Sookmyung Women's University; Seoul, Korea
}

\begin{abstract}
This study analyzes the characteristics by age and type for middle aged and elderly women foot shapes aged 40-69 years. ANOVA, factor, and cluster analyzed middle aged and elderly women's foot shapes. The results of the study are as follows. First, higher age groups tended to have smaller foot lengths, ball/instep circumferences, circumferences, and ball heights with larger heel height values and higher degrees of gathering of toe 1 and toe 5 toward the feet reference axis. Second, foot lengths were $220 \mathrm{~mm}-240 \mathrm{~mm}$ and the ball circumference's size symbol in high frequency sections were distributed from E to EEEE in the 40s and 60s groups and from D to EEEE in the 50s group. Third, eight factors were extracted through the factor analyses of middle aged and elderly women's foot measurement items. Fourth, a cluster analyses classified the subjects into four types. Type 1 is a normal foot type with medium foot length and small ball circumference and type 2 is a long and flat foot type with a type with large foot length and ball circumference values as well as small ball height values. Type 3 is a thick foot type with a medium foot length, large ball circumference, large ball height and type 4 is a toe deformation foot type with medium foot length, small ball circumference, and a high degree of toe gathering toward the center.
\end{abstract}

Key words : middle aged and elderly women, foot shape, foot measurement, 3D scan, shoes size

\section{Introduction}

The feet are an important organ that support and move the human bodies while humans are standing or walking. Since modern people are wearing their shoes on for most of activity time during daily living, along with functions to protect feet and absorb impacts, functions to prevent changes in foot shapes and provide comfortable wearing sensations are important requirements for shoes(Chun \& Choi, 1999; Kim \& Do, 2014; Lim, 2007). Therefore, to make shoes that fit human feet, analyses of foot sizes, shapes, and characteristics should precede. To review previous studies on foot shapes, $\operatorname{Lim}(2007)$ directly and indirectly measured the feet of middle school girls aged 14 16 years and divided foot shapes into three types through factor analyses and cluster analyses of the resultant foot measures.

Park and Nam(2004) measured the feet of young women aged 18 30 years and those of elderly women aged at least 60 years directly and indirectly using digital cameras and analyzed the resultant foot shapes. They reported that when foot index values were compared, elderly women's feet showed higher ratios of foot breadths to foot lengths and lower foot heights compared to young women thereby showing elliptical flattening. In addition, they reported that elderly women's feet showed shorter toe parts compared to foot lengths, wider lateral regions than medial regions, and

$\dagger$ Corresponding author; Ho-Sun Lim

Tel. +82-2-2077-7121, Fax. +82-2-2077-7324

E-mail: lhs@sm.ac.kr smaller toe breadths compared to foot breadths thereby showing a tendency to have many deformations of the toe region or the foot reference axis. Park and Chae(2008) measured the feet of women aged at least 30 years directly and indirectly using the foot printer method, analyzed foot characteristics by age using the foot measures, and derived a regression equation using foot lengths and ball circumferences as representative items. They reported that the group showed a tendency to have larger widths of the region below the lateral malleolus, smaller toe breadths, ball circumferences, instep circumferences, and heel-to-instep circumferences, and toe 1 and toe 5 closer to the foot reference axis as they became older. Park(2011) analyzed foot shapes and sole types using data of adult women aged 20 59 years out of the 5th Size Korea data. He reported that the women showed a tendency toward increases in ball widths, heel widths, toe 1 heights, lateral malleolus heights, heel heights, ball heights, circumference items, and the thickness of the ankle along with their age. Lee and Do(2013) analyzed high school girls' sole types using the two-dimensional indirect measurement method to find out that there were differences between the left foot and the right foot and divided the soles into three sole types through cluster analyses. Kim and Do(2014) analyzed the foot shapes of elderly women aged at least 60 years using threedimensional and two-dimensional measurement methods and divided the foot shapes into three types; a type with high front and center parts, a type with high front part and low center part, and a type with low front part and high center part of the foot. In addition, they divided sole shapes into three types; H, D, and A and reported 
that elderly women's feet showed a tendency toward larger ball sizes compared to foot lengths and high foot center parts. Suh and Suk(2003) measured the feet of adult women aged at least 20 years directly and indirectly and analyzed the subjects' foot shapes through ANOVA analyses, factor analyses, and cluster analyses of foot measures. They reported that the subjects showed a tendency toward higher ratios of foot breadths to foot lengths, decreases in foot heights, and increases in the degree of deformation of toe 1 and toe 5 along with increases in the subjects' ages.

As such, studies on the foot shapes of diverse age groups have been actively conducted such studies conducted with youths, comparative studies conducted with young and elderly adults, studies conducted with adults aged at least 30 years, and studies conducted with adults aged at least 60 years. As the economic influence of middle aged and elderly adults is gradually growing and the consumer markets for new senior groups are becoming bigger, studies with middle aged and elderly adults in their 40 60s that are emerging as important consumer groups in the fashion industry area(Choi et al., 2011; Chung, 2013; Kim, 2011) are considered necessary. Therefore, the present study is intended to examine the foot shapes of middle aged and elderly adult females in their 40 60s experiencing continuous declines in musculoskeletal system functions, reduction in physical strength, and changes in body shapes as the aging phenomenon gradually progresses after they have entered into mid to late adulthood.

In addition, recently, comfort shoes that are light-weighted and have comfortable wearing sensations have been actively developed for middle aged consumers(Park \& Chae, 2008) and consumers' interest in shoes' functionality and wearing sensations has been continuously increasing. To produce shoes that fit the feet well with comfortable wearing sensations reflecting these trends, the characteristics of foot shapes of middle aged and elderly persons by age should be accurately analyzed and studies on the design of lasts reflecting consumers' foot shapes and dimensions based on the results of the analysis are necessary.

Therefore, the purpose of the present study is to analyze the characteristics of the foot shapes of middle aged and elderly women aged $40 \sim 69$ years by age and by type in order to provide basic data for design of lasts suitable for the foot shapes of the consumers.

\section{Methods}

\subsection{Study subjects}

The present study used data from the 3D body shape measurement project of middle aged and elderly persons implemented from August 31 to December 25, 2012 as part of the 6th Size Korea Proj-
ect(Korean Agency for Technology and Standards, 2012). The study subjects were women of 40 69 years residing in the capital region. The data on 606 subjects out of 610 subjects were used except for data on 4 subjects that the sizes of all foot measurement items were missing.

\subsection{Measurement items}

As for measurement items, data on 24 foot measurement items measured sing Enfoot System 3D Foot scanners of K\&I Technology out of the 3D body shape measurement data were used. The foot measurement reference points and measurement items are as
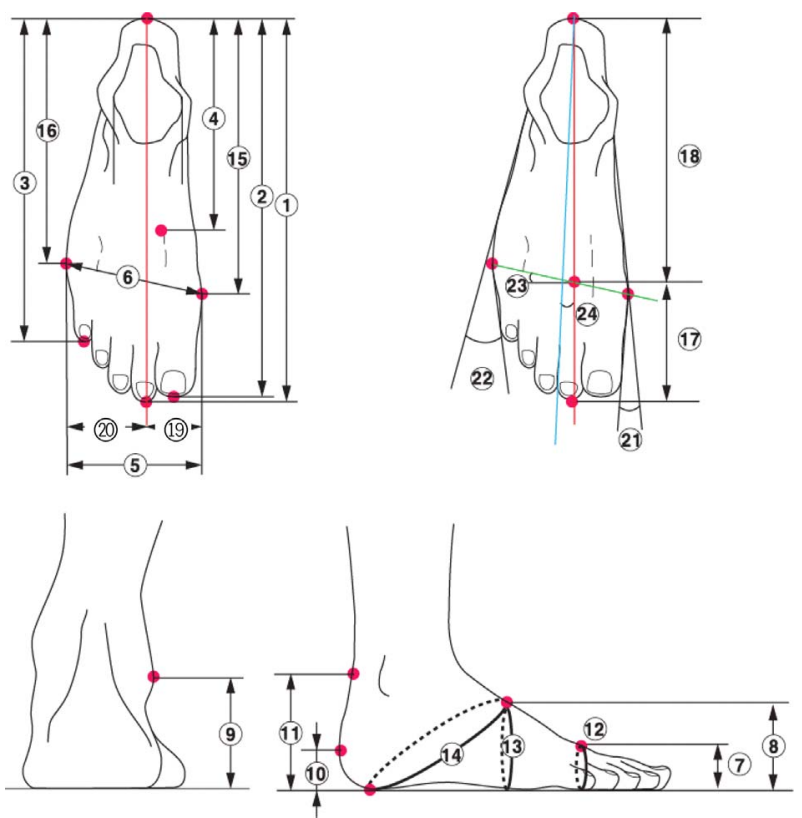

Fig. 1. 3D foot measurement items. Korean Agency for Technology and Standards (2012), p. 77.

Table 1. Foot measurement items

\begin{tabular}{lll}
\hline No. & \multicolumn{1}{c}{ Items } & \multicolumn{1}{c}{ Items } \\
\hline 1 Foot length & 13 Instep circumference \\
2 Heel-to-toe 1 length & 14 Heel-to-instep circumference \\
3 Heel-to-toe 5 length & 15 Medial ball length \\
4 Heel-to-instep length & 16 Lateral ball length \\
5 Foot breadth & 17 Ball center-to-toe 2 length \\
6 Ball distance & 18 Ball center-to-heel length \\
7 Ball height & 19 Medial ball width \\
8 Instep height & 20 Lateral ball width \\
9 Lateral malleolus height & 21 Toe 1 angle \\
10 Heel height & 22 Toe 5 angle \\
11 Height of upper point of & 23 Ball angle \\
heel point & 24 Ball center angle \\
\hline Korean Agency for Technology and Standards (2012), p. 76.
\end{tabular}


shown in Fig. 1 and Table 1.

\subsection{Analysis method}

The data in the present study were statistically processed using the IBM SPSS Statistics 22 program. Analyses of variance(ANOVAs) and Duncan posteriori tests were conducted to analyze differences in individual measurement items between ages. The distributions of foot lengths and ball circumferences among age groups were analyzed through cross-tabulations. In addition, factor analyses were conducted to derive the constituting factors of middle aged and elderly women's foot shapes and cluster analyses were conducted to classify foot shapes by type. To examine differences among the classified types, ANOVAs and Duncan posteriori tests of the mean values of individual measurement item were conducted.

\section{Results and Discussion}

\subsection{Comparison of measured foot dimensions among} ages

The middle aged and elderly women aged 40 69 years were divided into 40s, 50s, and 60s groups and ANOVAs of measured feet dimensions by age group were conducted. The results are as shown in Table 2.

To examine differences in the mean values of measured feet dimensions among the age groups, all length items except for medial ball lengths showed significant differences among the age groups. The items foot lengths and heel-to-toe 1 lengths showed lower mean values in the $60 \mathrm{~s}$ group compared to the $40 \mathrm{~s}$ and $50 \mathrm{~s}$ and the item heel-to-toe 5 lengths showed the highest mean value in the 40 s group followed by the 50 s group and the 60 s group in

Table 2. Results of ANOVAs of measured feet dimensions by age

\begin{tabular}{|c|c|c|c|c|c|c|c|c|c|c|}
\hline & \multirow[b]{2}{*}{ Dimensions } & \multicolumn{2}{|c|}{$\begin{array}{c}40 \sim 49 \text { years } \\
(\mathrm{N}=200)\end{array}$} & \multicolumn{2}{|c|}{$\begin{array}{c}50 \sim 59 \text { years } \\
(\mathrm{N}=207)\end{array}$} & \multicolumn{2}{|c|}{$\begin{array}{c}60 \sim 69 \text { years } \\
(\mathrm{N}=199)\end{array}$} & \multicolumn{2}{|c|}{$\begin{array}{c}\text { Total } \\
(\mathrm{N}=606)\end{array}$} & \multirow{2}{*}{ F-value } \\
\hline & & Mean & S.D. & Mean & S.D. & Mean & S.D. & Mean & S.D. & \\
\hline \multirow{8}{*}{ 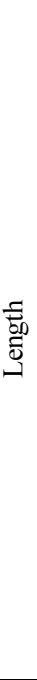 } & 1 Foot length & $\begin{array}{c}228.42 \\
\mathrm{~A}\end{array}$ & 9.63 & $\begin{array}{c}226.76 \\
\text { A }\end{array}$ & 8.96 & $\begin{array}{c}224.78 \\
\text { B }\end{array}$ & 8.99 & 226.66 & 9.30 & $7.83^{* * *}$ \\
\hline & 2 Heel-to-toe 1 length & $\begin{array}{c}228.16 \\
\text { A }\end{array}$ & 9.66 & $\begin{array}{c}226.50 \\
\text { A }\end{array}$ & 8.98 & $\begin{array}{c}224.51 \\
\text { B }\end{array}$ & 8.93 & 226.39 & 9.30 & $7.89^{* * *}$ \\
\hline & 3 Heel-to-toe 5 length & $\begin{array}{c}187.59 \\
\text { A }\end{array}$ & 8.18 & $\begin{array}{c}185.95 \\
\text { B }\end{array}$ & 7.78 & $\begin{array}{c}184.40 \\
\mathrm{C}\end{array}$ & 7.66 & 185.98 & 7.97 & $8.18^{* * *}$ \\
\hline & 4 Heel-to-instep length & $\begin{array}{c}122.31 \\
\text { B }\end{array}$ & 8.96 & $\begin{array}{c}124.30 \\
\mathrm{~A}\end{array}$ & 8.13 & $\begin{array}{c}123.82 \\
\mathrm{AB}\end{array}$ & 7.69 & 123.49 & 8.31 & $3.21^{*}$ \\
\hline & 15 Medial ball length & $\begin{array}{c}166.93 \\
\text { A }\end{array}$ & 8.45 & $\begin{array}{c}166.75 \\
\text { A }\end{array}$ & 6.88 & $\begin{array}{c}165.55 \\
\mathrm{~A}\end{array}$ & 7.26 & 166.41 & 7.56 & 1.98 \\
\hline & 16 Lateral ball length & $\begin{array}{c}144.76 \\
\mathrm{AB}\end{array}$ & 8.00 & $\begin{array}{c}145.87 \\
\text { A }\end{array}$ & 7.27 & $\begin{array}{c}143.89 \\
\text { B }\end{array}$ & 7.30 & 144.85 & 7.56 & $3.54^{*}$ \\
\hline & 17 Ball center-to-toe 2 length & $\begin{array}{c}66.12 \\
\text { B }\end{array}$ & 8.52 & $\begin{array}{c}68.39 \\
\mathrm{~A}\end{array}$ & 10.87 & $\begin{array}{c}66.38 \\
\text { B }\end{array}$ & 8.19 & 66.98 & 9.33 & $3.68^{*}$ \\
\hline & 18 Ball center-to-heel length & $\begin{array}{c}158.48 \\
\text { A }\end{array}$ & 10.25 & $\begin{array}{c}154.83 \\
\text { B }\end{array}$ & 12.05 & $\begin{array}{c}155.67 \\
\text { B }\end{array}$ & 11.29 & 156.31 & 11.32 & $5.86^{* *}$ \\
\hline \multirow{4}{*}{ 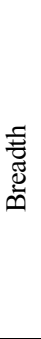 } & 5 Foot breadth & $\begin{array}{c}88.94 \\
\text { A }\end{array}$ & 4.82 & $\begin{array}{c}89.49 \\
\text { A }\end{array}$ & 4.64 & $\begin{array}{c}89.23 \\
\mathrm{~A}\end{array}$ & 4.81 & 89.22 & 4.75 & 0.69 \\
\hline & 6 Ball distance & $\begin{array}{c}91.85 \\
\mathrm{~A}\end{array}$ & 4.98 & $\begin{array}{c}92.11 \\
\mathrm{~A}\end{array}$ & 4.75 & $\begin{array}{c}91.99 \\
\mathrm{~A}\end{array}$ & 4.82 & 91.98 & 4.84 & 0.15 \\
\hline & 19 Medial ball width & $\begin{array}{c}39.99 \\
\text { B }\end{array}$ & 4.30 & $\begin{array}{c}41.09 \\
\mathrm{~A}\end{array}$ & 4.36 & $\begin{array}{c}41.24 \\
\mathrm{~A}\end{array}$ & 5.24 & 40.78 & 4.67 & $4.32^{*}$ \\
\hline & 20 Lateral ball width & $\begin{array}{c}48.99 \\
\text { A }\end{array}$ & 4.07 & $\begin{array}{c}48.41 \\
\mathrm{AB}\end{array}$ & 3.67 & $\begin{array}{c}48.04 \\
\text { B }\end{array}$ & 4.18 & 48.48 & 3.99 & 2.86 \\
\hline \multirow{3}{*}{ 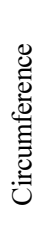 } & 12 Ball circumference & $\begin{array}{c}235.36 \\
\text { A }\end{array}$ & 13.64 & $\begin{array}{c}229.01 \\
\mathrm{C}\end{array}$ & 10.49 & $\begin{array}{c}231.9 \\
\text { B }\end{array}$ & 12.89 & 232.05 & 12.65 & $13.37^{* * *}$ \\
\hline & 13 Instep circumference & $\begin{array}{c}230.42 \\
\text { A }\end{array}$ & 12.78 & $\begin{array}{c}224.79 \\
\text { B }\end{array}$ & 9.77 & $\begin{array}{c}226.38 \\
\text { B }\end{array}$ & 11.33 & 227.17 & 11.57 & $13.25^{* * *}$ \\
\hline & 14 Heel-to-instep circumference & $\begin{array}{c}341.62 \\
\text { A }\end{array}$ & 27.03 & $\begin{array}{c}343.68 \\
\text { A }\end{array}$ & 31.33 & $\begin{array}{c}346.54 \\
\text { A }\end{array}$ & 28.30 & 343.91 & 28.98 & 1.42 \\
\hline
\end{tabular}


Table 2. Continued

\begin{tabular}{|c|c|c|c|c|c|c|c|c|c|c|}
\hline & \multirow[b]{2}{*}{ Dimensions } & \multicolumn{2}{|c|}{$\begin{array}{c}40 \sim 49 \text { years } \\
(\mathrm{N}=200)\end{array}$} & \multicolumn{2}{|c|}{$\begin{array}{c}50 \sim 59 \text { years } \\
(\mathrm{N}=207)\end{array}$} & \multicolumn{2}{|c|}{$\begin{array}{c}60 \sim 69 \text { years } \\
(\mathrm{N}=199)\end{array}$} & \multicolumn{2}{|c|}{$\begin{array}{c}\text { Total } \\
(\mathrm{N}=606)\end{array}$} & \multirow{2}{*}{ F-value } \\
\hline & & Mean & S.D. & Mean & S.D. & Mean & S.D. & Mean & S.D. & \\
\hline \multirow{5}{*}{ 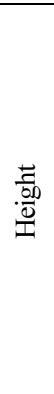 } & 7 Ball height & $\begin{array}{c}33.92 \\
\mathrm{~A}\end{array}$ & 2.81 & $\begin{array}{c}32.69 \\
\text { B }\end{array}$ & 2.53 & $\begin{array}{c}32.91 \\
\mathrm{~B}\end{array}$ & 2.38 & 33.17 & 2.63 & $12.89^{* * *}$ \\
\hline & 8 Instep height & $\begin{array}{c}55.17 \\
\mathrm{~A}\end{array}$ & 4.86 & $\begin{array}{c}53.79 \\
\text { B }\end{array}$ & 4.69 & $\begin{array}{c}53.83 \\
\mathrm{~B}\end{array}$ & 4.56 & 54.26 & 4.74 & $5.56^{* *}$ \\
\hline & 9 Lateral malleolus height & $\begin{array}{c}63.39 \\
\text { A }\end{array}$ & 4.42 & $\begin{array}{c}63.37 \\
\text { A }\end{array}$ & 5.03 & $\begin{array}{c}62.44 \\
\mathrm{~A}\end{array}$ & 5.53 & 63.07 & 5.02 & 2.36 \\
\hline & 10 Heel height & $\begin{array}{c}23.67 \\
\mathrm{~B}\end{array}$ & 3.13 & $\begin{array}{c}25.82 \\
\mathrm{~A}\end{array}$ & 3.34 & $\begin{array}{c}26.08 \\
\mathrm{~A}\end{array}$ & 3.64 & 25.20 & 3.54 & $30.83^{* * *}$ \\
\hline & 11 Height of upper point of heel point & $\begin{array}{c}38.03 \\
\mathrm{~B}\end{array}$ & 4.55 & $\begin{array}{c}41.11 \\
\mathrm{~A}\end{array}$ & 5.87 & $\begin{array}{c}40.88 \\
\mathrm{~A}\end{array}$ & 4.64 & 40.02 & 5.25 & $23.17^{* * *}$ \\
\hline \multirow{4}{*}{$\frac{\frac{0}{60}}{\frac{b}{<}}$} & 21 Toe 1 angle & $\begin{array}{c}7.81 \\
\mathrm{~B}\end{array}$ & 9.09 & $\begin{array}{c}11.34 \\
\mathrm{~A}\end{array}$ & 11.57 & $\begin{array}{c}12.03 \\
\mathrm{~A}\end{array}$ & 12.00 & 10.4 & 11.10 & $8.58^{* * *}$ \\
\hline & 22 Toe 5 angle & $\begin{array}{c}12.78 \\
\mathrm{~B}\end{array}$ & 10.56 & $\begin{array}{c}15.50 \\
\mathrm{~A}\end{array}$ & 13.01 & $\begin{array}{c}15.44 \\
\mathrm{~A}\end{array}$ & 11.64 & 14.58 & 11.84 & $3.48^{*}$ \\
\hline & 23 Ball angle & $\begin{array}{c}13.95 \\
\mathrm{~A}\end{array}$ & 3.64 & $\begin{array}{c}13.10 \\
\mathrm{~B}\end{array}$ & 3.39 & $\begin{array}{c}13.60 \\
\mathrm{AB}\end{array}$ & 3.07 & 13.55 & 3.39 & $3.26^{*}$ \\
\hline & 24 Ball center angle & $\begin{array}{c}1.75 \\
\mathrm{~A}\end{array}$ & 1.15 & $\begin{array}{c}1.52 \\
\mathrm{~A}\end{array}$ & 0.99 & $\begin{array}{c}1.62 \\
\mathrm{~A}\end{array}$ & 1.13 & 1.627 & 1.09 & 2.09 \\
\hline
\end{tabular}

Duncan test: $\mathrm{A}>\mathrm{B}>\mathrm{C}$

${ }^{* * *} p<.001, \stackrel{* * *}{p}<<.01,{ }^{*} p<.05$

order of precedence. The item ball center-to-heel lengths showed the highest mean value in the 40s and generally showed a tendency toward higher mean values in lower age groups. On the other hand, the items heel-to-instep lengths, lateral ball lengths, and ball centerto-toe 2 lengths higher mean values in the 50 s group compared to other age groups.

Most width items did not show any significant difference among ages. Among circumference items, the items, ball circumferences and instep circumferences showed the highest mean values in the 40s group compared to other age groups. All height items except for lateral malleolus heights showed significant differences among the ages. The items ball heights and instep heights showed the highest mean values in the 40 s with a tendency toward higher mean values in lower age groups. On the other hand, the items heel heights and the heights of the upper point of the heel point showed the lowest mean values in the 40s group and showed a tendency toward lower mean values in lower age groups.

Among angle items, the items toe 1 angles and toe 5 angles showed higher mean values in the $50 \mathrm{~s}$ and 60 s groups compared to the 40 s and showed a tendency toward higher mean values in higher age groups. On the other hand the item ball angles showed a higher mean value in the 40 s group.

As described above, the items foot lengths, heel-to-toe 1 lengths, heel-to-toe 5 lengths, ball center-to-heel lengths, ball circumferences, instep circumferences, ball heights, and instep heights showed a tendency toward lower mean values of measured dimen- sions in higher age groups. On the other hand, the items, heel heights, the heights of the upper point of the heel point, medial ball widths, toe 1 angles, and toe 5 angles showed a tendency toward higher mean values of measured dimensions in higher age groups.

\subsection{Analysis of shoes sizes according to ages}

As a shoes size system, sizes were divided using foot lengths and ball circumferences as basic dimensions referring to the Korean Industrial standard KS G 3405. The KS G 3405 standard classifies foot lengths at $5 \mathrm{~mm}$ intervals and ball circumferences at $3 \mathrm{~mm}$ intervals and since ball circumference sizes increase at intervals of $6 \mathrm{~mm}$ in the same foot length section, the standard presents seven ball circumference's size symbols; B, C, D, E, EE, EEE, and EEEE. As such, foot lengths were divided at intervals of $5 \mathrm{~mm}$ and ball circumferences at $3 \mathrm{~mm}$ intervals and ball circumference's size symbols were divided at $6 \mathrm{~mm}$ intervals in each of foot lengths sections. Thereafter, cross tabulations were conducted to examine shoe size distributions according to age groups.

Table 3 shows the distribution of shoe last sizes of the women from $40 \mathrm{~s}$ to $60 \mathrm{~s}$. Of all the foot lengths of women from $40 \mathrm{~s}$ to $60 \mathrm{~s}$, $82.3 \%$ was distributed between $220 \mathrm{~mm}$ and $240 \mathrm{~mm}$. To review high frequency(at least 3.0\%) sections in this range, two sections corresponding to ball circumference's size symbols EE and EEE at foot length $220 \mathrm{~mm}$, three sections corresponding to ball circumference's size symbols E, EE, and EEE at foot length $225 \mathrm{~mm}$, three sections corresponding to ball circumference's size symbols E, EE 
Table 3. Distribution of shoe last sizes of the women from $40 \mathrm{~s}$ to $60 \mathrm{~s}$

\begin{tabular}{|c|c|c|c|c|c|c|c|c|c|c|c|c|}
\hline $\begin{array}{l}\text { Foot length } \\
\text { circumference }\end{array}$ & 205 & 210 & 215 & 220 & 225 & 230 & 235 & 240 & 245 & 250 & 255 & Total \\
\hline 300 & & & 1 & 1 & 1 & 1 & 5 & 3 & 1 & 2 & \multirow{2}{*}{2} & 16 \\
\hline 257 & & & & 1 & 1 & 2 & & 1 & & & & 6 \\
\hline 254 & & & & 1 & 2 & 1 & 5 & 3 & \multirow{2}{*}{4} & & \multirow{2}{*}{1} & 14 \\
\hline 251 & & & & 1 & 2 & 2 & 5 & 5 & & 1 & & 15 \\
\hline 248 & & & 2 & 1 & 1 & 3 & \multirow{2}{*}{17} & 3 & \multirow{2}{*}{9} & 1 & & 21 \\
\hline 245 & & & & & 3 & \multirow{2}{*}{17} & & \multirow{2}{*}{17} & & \multirow{2}{*}{4} & & 38 \\
\hline 242 & & 1 & 1 & 5 & \multirow{2}{*}{16} & & \multirow{2}{*}{22} & & \multirow{2}{*}{3} & & \multirow{2}{*}{1} & 43 \\
\hline 239 & & & & 0 & & \multirow{2}{*}{30} & & \multirow{2}{*}{18} & & & & 50 \\
\hline 236 & & 2 & 2 & 9 & \multirow{2}{*}{22} & & \multirow{2}{*}{25} & & \multirow{2}{*}{3} & & & 56 \\
\hline 233 & & \multirow{2}{*}{1} & 3 & \multirow{2}{*}{19} & & \multirow{2}{*}{30} & & \multirow{2}{*}{10} & & ? & & 63 \\
\hline 230 & & & \multirow{2}{*}{11} & & \multirow{2}{*}{28} & & \multirow{2}{*}{15} & & \multirow{2}{*}{6} & 2 & & 66 \\
\hline 227 & & \multirow{2}{*}{5} & & \multirow{2}{*}{27} & & \multirow{2}{*}{23} & & \multirow{2}{*}{5} & & & & 49 \\
\hline 224 & 2 & & 0 & & \multirow{2}{*}{18} & & 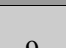 & & 1 & & & 57 \\
\hline 221 & 3 & \multirow{2}{*}{10} & 9 & 12 & & & 9 & 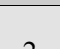 & 1 & & & 34 \\
\hline 218 & & & ( & 13 & o & 11 & 2 & 2 & & & & 32 \\
\hline 215 & & 2 & 6 & 1 & 9 & 6 & 3 & 1 & & & & 17 \\
\hline 212 & & 3 & 3 & 10 & 3 & 0 & 1 & & & & & 16 \\
\hline 209 & & 3 & 3 & 6 & 3 & & & & & & & 6 \\
\hline 206 & & 3 & & 0 & & 1 & & & & & & 4 \\
\hline 203 & & ? & & & & & & & & & & 2 \\
\hline 200 & 1 & 2 & & & & & & & & & & 1 \\
\hline Total & 4 & 27 & 36 & 94 & 106 & 127 & 107 & 65 & 27 & 9 & 4 & 606 \\
\hline $\begin{array}{c}\text { Circumference } \\
\text { symbol }\end{array}$ & & $\mathrm{C}$ & & D & & E & & & $\mathrm{EEI}$ & & EEEE & \\
\hline
\end{tabular}

and EEE at foot length $230 \mathrm{~mm}$, two sections corresponding to ball circumference's size symbols EE and EEE at foot length $235 \mathrm{~mm}$, one section corresponding to ball circumference's size symbol EE at foot length $240 \mathrm{~mm}$ were shown to be high frequency sections. Of all the ball circumferences in this range, $74.3 \%$ was distributed between $221 \mathrm{~mm}$ and $242 \mathrm{~mm}$.

Table 4 shows the distribution of shoe last sizes of the women in their $40 \mathrm{~s}$. Of all the foot lengths of women in their $40 \mathrm{~s}, 81.0 \%$ was distributed between $220 \mathrm{~mm}$ and $240 \mathrm{~mm}$. To review high frequency (at least 3.0\%) sections in this range, two sections corresponding to ball circumference's size symbols EE and EEE at foot length $220 \mathrm{~mm}$, one section corresponding to ball circumference's size symbol EEE at foot length $225 \mathrm{~mm}$, four sections corresponding to ball circumference's size symbols E, EE, EEE, and EEEE at foot length $230 \mathrm{~mm}$, three sections corresponding to ball circumference's size symbols EE, EEE, and EEEE at foot length 235mm, and one section corresponding to ball circumference's size symbol EEE at foot length $240 \mathrm{~mm}$ were shown to be high frequency sec- tions. Of all the ball circumferences in this range, $70.0 \%$ was distributed between $224 \mathrm{~mm}$ and $248 \mathrm{~mm}$.

Table 5 shows the distribution of shoe last sizes of the women in their $50 \mathrm{~s}$. Of all foot lengths of the women in their $50 \mathrm{~s}, 84.5 \%$ was distributed between $220 \mathrm{~mm}$ and $240 \mathrm{~mm}$. To review high frequency(at least 3.0\%) sections in this range, two sections corresponding to ball circumference's size symbols EE and EEE at foot length $220 \mathrm{~mm}$, four sections corresponding to ball circumference's size symbols D, E, EE, EEEE at foot length $225 \mathrm{~mm}$, three sections corresponding to ball circumference's size symbols EE, EE, and EEE at foot length $230 \mathrm{~mm}$, two sections corresponding to ball circumference's size symbols E and EE at foot length $235 \mathrm{~mm}$, and two sections corresponding to ball circumference's size symbols EEE and EEEE at foot length $240 \mathrm{~mm}$ were shown to be high frequency sections. Of all the ball circumferences in this range, $89.4 \%$ was distributed between $215 \mathrm{~mm}$ and $245 \mathrm{~mm}$.

Table 6 shows the distribution of shoe last sizes of the women in their $60 \mathrm{~s}$. Of all the foot lengths of women in their $60 \mathrm{~s}, 75.4 \%$ was 
Table 4. Distribution of shoe last sizes of the women in their 40s

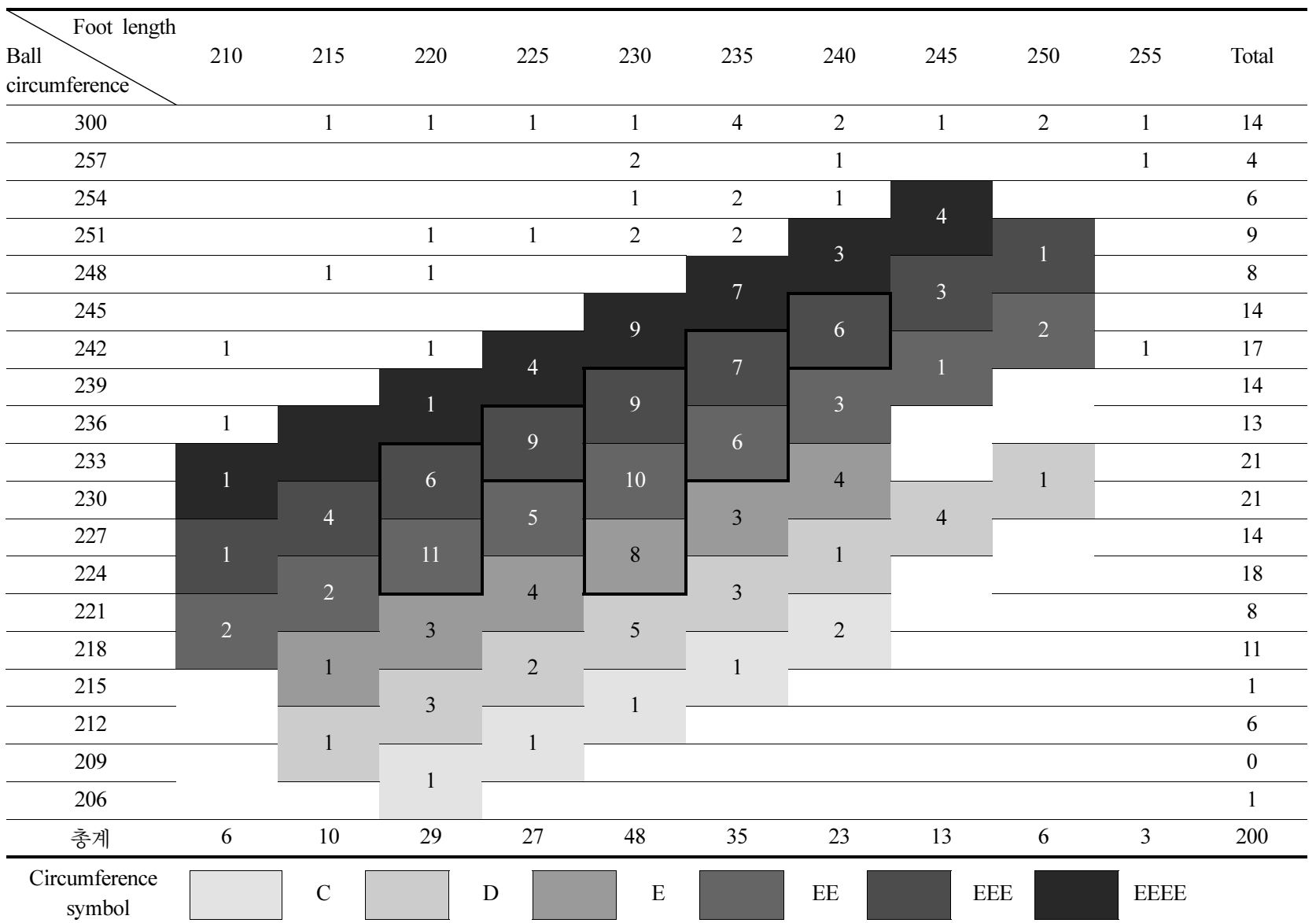

distributed between $220 \mathrm{~mm}$ and $235 \mathrm{~mm}$. To review high frequency(at least 3.0\%) sections in this range, three sections corresponding to ball circumference's size symbols E, EE, and EEE at foot length $220 \mathrm{~mm}$, four sections corresponding to ball circumference's size symbols E, EE, EEE, and EEEE at foot length $225 \mathrm{~mm}$, two sections corresponding to ball circumference's size symbols EE and EEE at foot length $230 \mathrm{~mm}$, two sections corresponding to ball circumference's size symbols $\mathrm{EE}$ and $\mathrm{EEE}$ at foot length $235 \mathrm{~mm}$ were shown to be high frequency sections. Of all the ball circumferences in this range, $75.9 \%$ was distributed between $218 \mathrm{~mm}$ and $242 \mathrm{~mm}$.

As described above, the foot lengths of women in their 40s were generally shown to be generally in a range of $220 \mathrm{~mm} \sim 240 \mathrm{~mm}$ and their ball circumference's size symbols in high frequency sections were distributed from $\mathrm{E}$ to EEEE. In particular, it could be seen that more diverse sections of ball circumference's size symbols were distributed at foot lengths $230 \mathrm{~mm}$ and $235 \mathrm{~mm}$ compared to other lengths. The foot lengths of women in their 50 s were generally shown to be generally in a range of $220 \mathrm{~mm} \sim 240 \mathrm{~mm}$ and their ball circumference's size symbols in high frequency sections were dis- tributed from D to EEEE. In particular, it could be seen that more diverse sections of ball circumference's size symbols were distributed at foot lengths $225 \mathrm{~mm}$ and $230 \mathrm{~mm}$ compared to other lengths.

The foot lengths of women in their 60 s were generally shown to be generally in a range of $220 \mathrm{~mm} \sim 235 \mathrm{~mm}$ and their ball circumference's size symbols in high frequency sections were distributed from $\mathrm{E}$ to EEEE. In particular, it could be seen that more diverse sections of ball circumference's size symbols were distributed at foot lengths $220 \mathrm{~mm}$ and $225 \mathrm{~mm}$ compared to other lengths.

As described above, the foot lengths of women in their 40s were generally shown to be generally in a range of $220 \mathrm{~mm} \sim 240 \mathrm{~mm}$ and their ball circumference's size symbols in high frequency sections were distributed from $\mathrm{E}$ to EEEE. In particular, it could be seen that more diverse sections of ball circumference's size symbols were distributed at foot lengths $230 \mathrm{~mm}$ and $235 \mathrm{~mm}$ compared to other lengths. The foot lengths of women in their 50 s were generally shown to be generally in a range of $220 \mathrm{~mm} \sim 240 \mathrm{~mm}$ and their ball circumference's size symbols in high frequency sections were distributed from D to EEEE. In particular, it could be seen that more diverse sections of ball circumference's size symbols were distrib- 
Table 5. Distribution of shoe last sizes of the women in their 50s

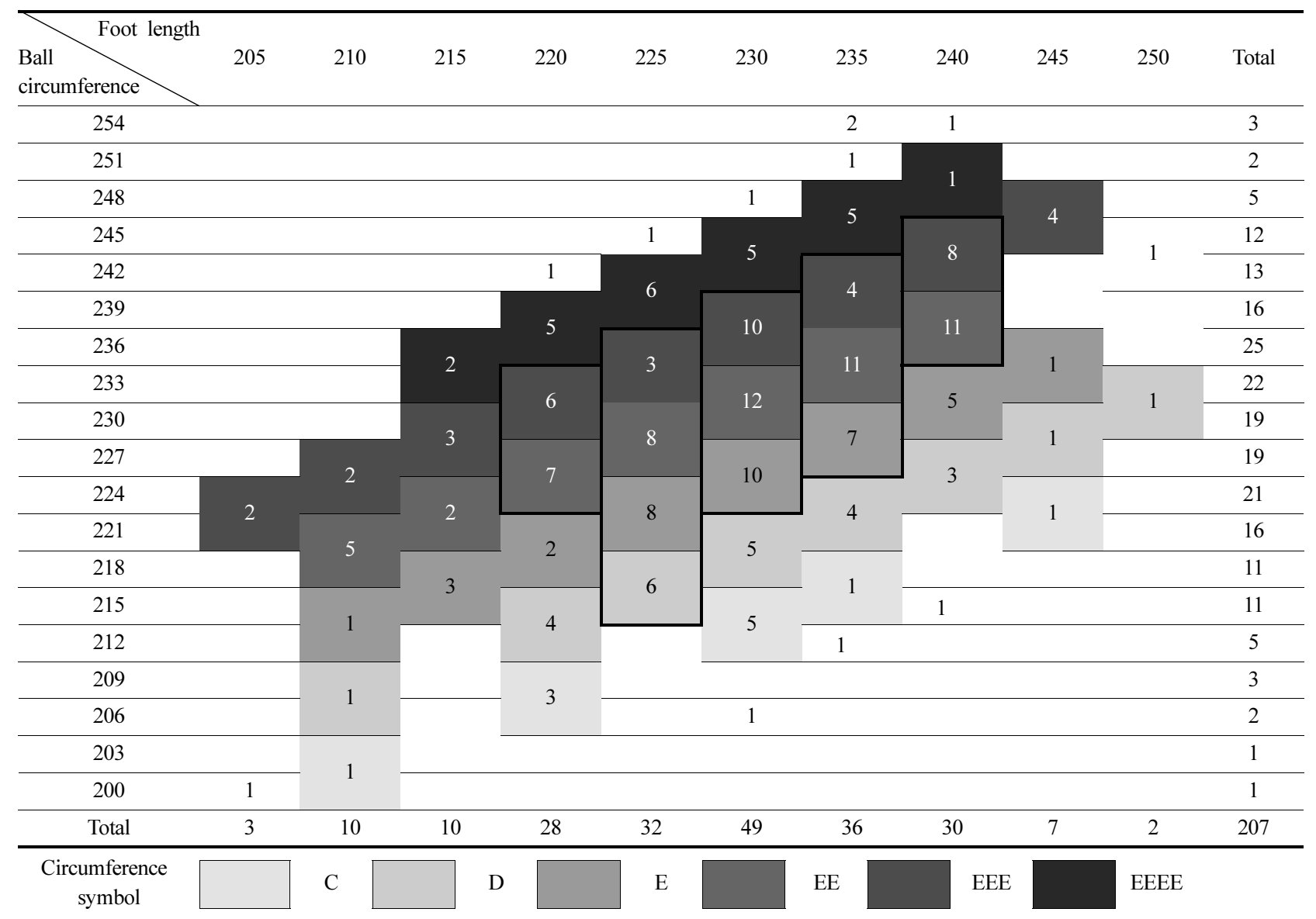

uted at foot lengths $225 \mathrm{~mm}$ and $230 \mathrm{~mm}$ compared to other lengths. The foot lengths of women in their 60 s were generally shown to be generally in a range of $220 \mathrm{~mm} \sim 235 \mathrm{~mm}$ and their ball circumference's size symbols in high frequency sections were distributed from $\mathrm{E}$ to EEEE. In particular, it could be seen that more diverse sections of ball circumference's size symbols were distributed at foot lengths $220 \mathrm{~mm}$ and $225 \mathrm{~mm}$ compared to other lengths.

As shown by the results described above, the foot lengths of women from 40 s to 60 s were generally shown to be generally in a range of $220 \mathrm{~mm} \sim 240 \mathrm{~mm}$ and their ball circumference's size symbols in high frequency sections were distributed from $\mathrm{E}$ to EEE. In particular, it could be seen that more diverse sections of ball circumference's size symbols were distributed at foot lengths $225 \mathrm{~mm}$ and $230 \mathrm{~mm}$ compared to other lengths.

\subsection{Factors of foot shape}

Factor analyses were conducted to derive constituting factors of their foot shapes. A total of eight factors were extracted that had an eigen value not smaller than 1 after orthogonal rotation with the Varimax method. Table 7 shows the results of the factor analyses of measured feet dimensions. The variance that can be explained by the eight factor is $83.43 \%$ of the entire variance.

Factor 1 has an eigen value of 5.32 and explains $22.17 \%$ of the entire variance. It has high loadings for foot lengths $(0.93)$, heel-totoe 1 lengths( $(0.93)$, medial ball lengths( 0.90$)$, heel-to-toe 5 lengths $(0.88)$, and lateral ball lengths $(0.86)$ and is interpreted as a factor that affects foot lengths.

Factor 2 has high loadings for ball distances(0.88), foot breadths( 0.87$)$, ball circumferences( 0.87$)$, and instep circumferences $(0.81)$ and is interpreted as a factor that affects ball circumferences and widths. It has an eigen value of 4.13 and explains $17.19 \%$ of the entire variance.

Factor 3 has an eigen value of 2.42 and explains $10.19 \%$ of the entire variance. It has high loadings for ball center angles(0.89), lateral ball widths( 0.81$)$, and medial ball widths(-0.78) and is interpreted as a factor that is involved in the medial and lateral shapes of toes on the basis of the ball center line. In factor 3, the loading for medial ball widths has a negative value indicating that medial ball widths have inverse relationships with other items.

Factor 4 has an eigen value of 1.91 and explains $7.94 \%$ of the 
Table 6. Distribution of shoe last sizes of the women in their $60 \mathrm{~s}$

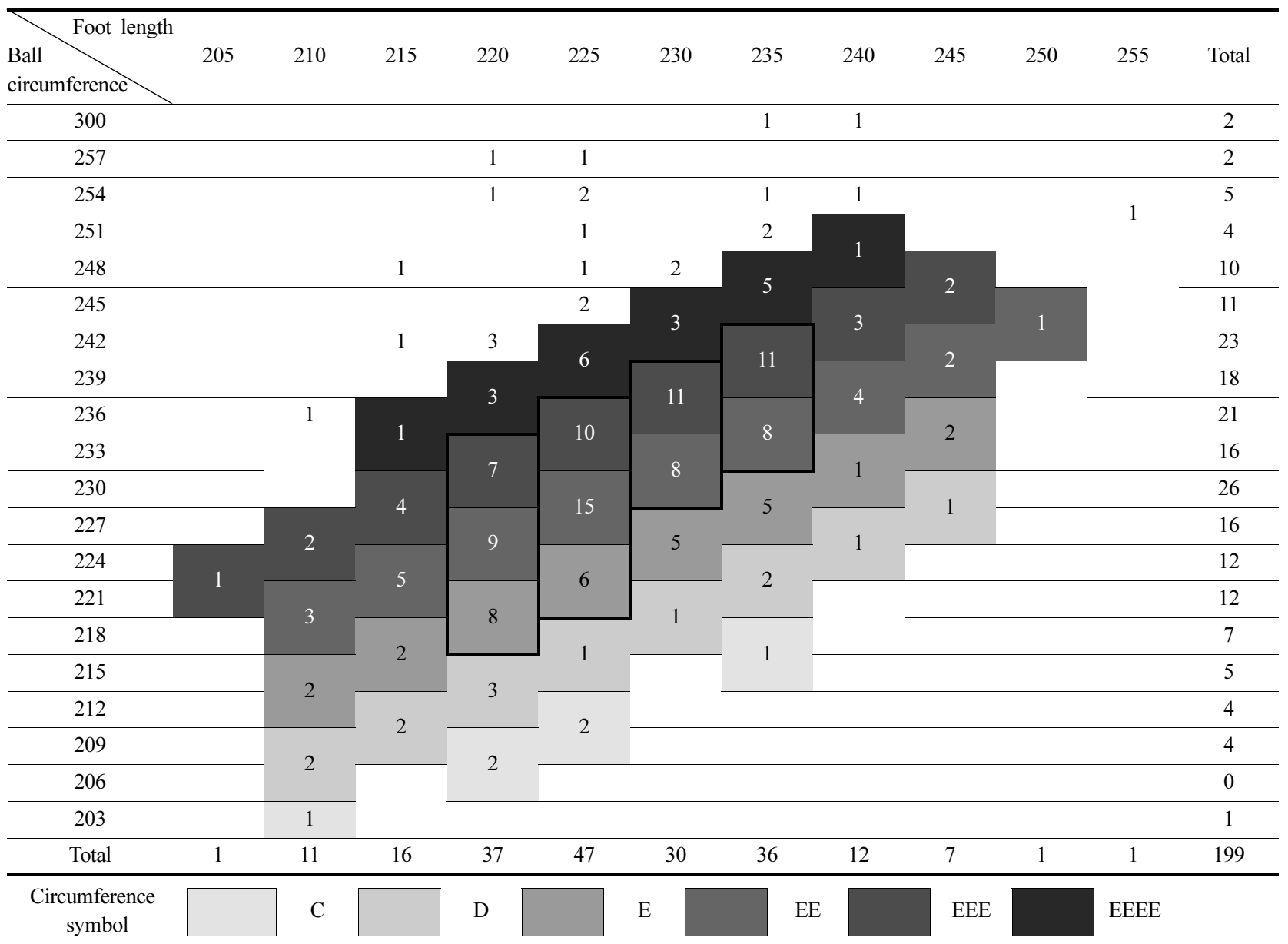

entire variance. It has high loadings for heel heights $(0.88)$ and the height of the upper point of the heel point $(0.80)$ and is interpreted as a factor that affects heel heights. Among the items of factor 4, lateral malleolus heights are not sufficiently significant and thus the relevant factor loading is splitted between factor 4 and factor 5 .

Factor 5 has an eigen value of 1.81 and explains $7.54 \%$ of the entire variance. It has high loadings for instep heights $(0.86)$ and heel-to-instep lengths $(-0.62)$ and is interpreted as a factor that affects the instep. In factor 5, the loadings for heel-to-instep lengths and heel-to-instep circumferences have negative values indicating that as the score of factor becomes larger, the values of loadings for these items become smaller. Among the items of factor 5, ball heights are not sufficiently significant and the relevant factor loading is splitted between factor 5 and factor 2 .

Factor 6 has an eigen value of 1.53 and explains $6.37 \%$ of the entire variance. It is interpreted as a factor that affects ball centerto-toe 2 lengths and ball center-to-heel lengths. It has high loadings for two items; ball center-to-toe 2 lengths( 0.95$)$ and ball center-toheel lengths(-0.68) and it can be seen that these two items are inversely related.

Factor 7 has an eigen value of 1.50 and explains $6.25 \%$ of the entire variance. It has high loadings for toe 5 angles $(0.83)$ and toe 1 angles $(0.78)$ and is interpreted as a factor that affects toe shapes.

Factor 8 has an eigen value of 1.41 and explains $5.87 \%$ of the entire variance. It has a high loading for ball angles $(0.98)$ and is interpreted as a factor that affects ball angles.

\subsection{Classification of foot shape}

To classify foot shapes by type, cluster analyses were conducted using the individual factors extracted through the factor analyses. Considering appearance ratios by type, the number of clusters by dendrogram and at which differences in the characteristics of foot shapes between clusters appear clearly, foot shapes were classified as four types. The subjects showed the following distribution: types $1 ; 340(57.5 \%)$, type $2 ; 135(22.8 \%)$, types $3 ; 80(13.5 \%)$, and types $4 ; 36(6.1 \%)$. The difference of foot shape by foot breadth appear clearly among four types. To examine the characteristics of foot shapes by the classified type, ANOVAs of factor scores and clus- 
Table 7. Results of the factor analyses of measured feet dimensions

\begin{tabular}{|c|c|c|c|c|c|c|c|c|c|}
\hline Factor & Factor & 1 & 2 & 3 & 4 & 5 & 6 & 7 & 8 \\
\hline \multirow{5}{*}{ Length } & 1 Foot length & 0.93 & 0.29 & -0.01 & 0.02 & 0.02 & 0.09 & 0.02 & 0.06 \\
\hline & 2 Heel-to-toe 1 length & 0.93 & 0.28 & -0.02 & 0.02 & 0.02 & 0.08 & 0.01 & 0.07 \\
\hline & 15 Medial ball length & 0.90 & 0.17 & -0.07 & 0.09 & -0.11 & -0.08 & 0.01 & 0.27 \\
\hline & 3 Heel-to-toe 5 length & 0.88 & 0.28 & 0.00 & 0.02 & 0.08 & 0.01 & -0.01 & -0.15 \\
\hline & 16 Lateral ball length & 0.86 & 0.03 & -0.06 & 0.06 & -0.02 & -0.08 & 0.04 & -0.43 \\
\hline \multirow{4}{*}{$\begin{array}{c}\text { Circumference- } \\
\text { breadth }\end{array}$} & 6 Ball distance & 0.25 & 0.88 & -0.08 & 0.14 & -0.12 & 0.05 & 0.16 & 0.08 \\
\hline & 5 Foot breadth & 0.24 & 0.87 & -0.09 & 0.13 & -0.09 & 0.04 & 0.18 & -0.21 \\
\hline & 12 Ball circumference & 0.23 & 0.87 & 0.05 & 0.01 & 0.08 & 0.04 & -0.02 & 0.12 \\
\hline & 13 Instep circumference & 0.23 & 0.81 & 0.15 & -0.01 & 0.17 & 0.01 & -0.07 & 0.01 \\
\hline \multirow{3}{*}{$\begin{array}{l}\text { Medial- } \\
\text { Lateral ball }\end{array}$} & 24 Ball center angle & -0.11 & 0.01 & 0.89 & -0.04 & 0.06 & -0.08 & 0.05 & -0.01 \\
\hline & 20 Lateral ball width & 0.14 & 0.44 & 0.81 & 0.02 & 0.04 & -0.01 & 0.05 & -0.07 \\
\hline & 19 Medial ball width & 0.14 & 0.50 & -0.78 & 0.11 & -0.13 & 0.06 & 0.14 & -0.15 \\
\hline \multirow{3}{*}{ Heel height } & 10 Heel height & -0.02 & 0.10 & -0.04 & 0.88 & -0.01 & -0.02 & 0.07 & 0.08 \\
\hline & 11 Height of upper point of heel point & 0.03 & 0.12 & -0.06 & 0.80 & -0.09 & 0.31 & 0.00 & -0.04 \\
\hline & 9 Lateral malleolus height & 0.23 & -0.03 & 0.05 & 0.53 & 0.41 & 0.01 & -0.15 & -0.09 \\
\hline \multirow{4}{*}{ Instep } & 8 Instep height & 0.10 & 0.23 & 0.19 & 0.11 & 0.86 & -0.02 & -0.05 & -0.08 \\
\hline & 4 Heel-to-instep length & 0.56 & 0.21 & 0.01 & 0.21 & -0.62 & -0.01 & -0.02 & 0.06 \\
\hline & 14 Heel-to-instep circumference & 0.33 & 0.28 & 0.19 & 0.16 & -0.46 & 0.04 & -0.13 & -0.11 \\
\hline & 7 Ball height & 0.12 & 0.44 & 0.28 & 0.12 & 0.44 & 0.10 & -0.24 & -0.09 \\
\hline \multirow{2}{*}{ Ball center } & 17 Ball center-to-toe 2 length & 0.09 & 0.14 & -0.07 & 0.17 & 0.00 & 0.95 & 0.03 & -0.01 \\
\hline & 18 Ball center-to-heel length & 0.68 & 0.11 & 0.07 & -0.11 & -0.01 & -0.68 & 0.02 & -0.01 \\
\hline \multirow{2}{*}{ Toe shape } & 22 Toe 5 angle & 0.06 & -0.03 & 0.26 & 0.02 & 0.00 & 0.02 & 0.83 & 0.04 \\
\hline & 21 Toe 1 angle & -0.02 & 0.19 & -0.27 & -0.02 & -0.06 & 0.00 & 0.78 & -0.14 \\
\hline \multirow[t]{3}{*}{ Ball angle } & 23 Ball angle & 0.00 & 0.00 & 0.00 & 0.02 & -0.09 & -0.01 & -0.07 & 0.98 \\
\hline & Eigenvalue & 5.32 & 4.13 & 2.42 & 1.91 & 1.81 & 1.53 & 1.50 & 1.41 \\
\hline & Variance $(\%)$ & 22.17 & 17.19 & 10.09 & 7.94 & 7.54 & 6.37 & 6.25 & 5.87 \\
\hline & ccumulative variance $(\%)$ & 22.17 & 39.36 & 49.45 & 57.39 & 64.93 & 71.31 & 77.56 & 83.43 \\
\hline
\end{tabular}

ters by foot shape types were conducted and Duncan tests were conducted as posteriori tests(Table 8). The results showed significant differences by type in six factors except for factor 5 heel height and factor 6 instep.

To examine the characteristics of individual types, ANOVAs and posteriori tests of feet measurement items were conducted and the results are as shown in Table 9.

Type 1 showed average measured values of the item medial ball length among items in factor 1 similar to those of type 2 and type 4 but higher than those of type 3 . On the other hand, type 1's average measured values of items foot length, heel-to-toe 1 length, medial ball length, heel-to-toe 5 length, and lateral ball length were shown to be similar to those of type 3 and type 4 and lower compared to those of type 2 . That is, type 2 showed a tendency to have the high- est values in most items in factor 1 that correspond to foot lengths.

Type 1 showed the lowest score for factor 2 that indicates ball circumferences-breadths compared to other types. Among the items in factor 2, the item foot breadth showed the most clear differences among four types. Type 2 showed the highest values followed by type 3 , type 4 , and type 1 in order of precedence indicating that type 1 had the smallest foot breadth.

In the case of factor 3 that indicates medial-lateral balls, type 1 showed intermediate average measured values of ball center angles which were lower compared to those of type 3 and higher compared to those of types 2 . Type 1 also showed intermediate average measured values of medial ball widths which were lower compared to those of types 2 and higher compared to those of types 3 . In the case of factor 4 that indicates heel heights, type 1 did not show any 
Table 8. Results of ANOVAs and posteriori tests of factor scores by foot shape type

\begin{tabular}{|c|c|c|c|c|c|c|}
\hline Factors & Types & $\begin{array}{c}\text { Type } 1 \\
(\mathrm{~N}=340)\end{array}$ & $\begin{array}{c}\text { Type } 2 \\
(\mathrm{~N}=135)\end{array}$ & $\begin{array}{l}\text { Type } 3 \\
(\mathrm{~N}=80)\end{array}$ & $\begin{array}{l}\text { Type } 4 \\
(\mathrm{~N}=36)\end{array}$ & F-value \\
\hline Factor 1 & Length & $\begin{array}{c}0.004 \\
\mathrm{~A}\end{array}$ & $\begin{array}{c}0.227 \\
\mathrm{~A}\end{array}$ & $\begin{array}{c}-0.385 \\
B\end{array}$ & $\begin{array}{c}0.017 \\
\mathrm{~A}\end{array}$ & $6.459^{* * *}$ \\
\hline Factor 2 & Circumference-breadth & $\begin{array}{c}-0.376 \\
\mathrm{C}\end{array}$ & $\begin{array}{c}0.495 \\
\mathrm{~B}\end{array}$ & $\begin{array}{c}0.809 \\
\mathrm{~A}\end{array}$ & $\begin{array}{c}-0.142 \\
\mathrm{C}\end{array}$ & $57.048^{* * *}$ \\
\hline Factor 3 & Medial-Lateral ball & $\begin{array}{c}-0.059 \\
\text { B }\end{array}$ & $\begin{array}{c}-0.665 \\
\mathrm{C}\end{array}$ & $\begin{array}{c}1.361 \\
\mathrm{~A}\end{array}$ & $\begin{array}{c}0.156 \\
\mathrm{~B}\end{array}$ & $109.108^{* * *}$ \\
\hline Factor 4 & Heel height & $\begin{array}{c}-0.072 \\
\mathrm{~A}\end{array}$ & $\begin{array}{c}0.174 \\
\mathrm{~A}\end{array}$ & $\begin{array}{c}-0.126 \\
\mathrm{~A}\end{array}$ & $\begin{array}{c}-0.071 \\
\mathrm{~A}\end{array}$ & 2.405 \\
\hline Factor 5 & Instep & $\begin{array}{c}0.005 \\
\mathrm{~A}\end{array}$ & $\begin{array}{c}0.059 \\
\mathrm{~A}\end{array}$ & $\begin{array}{c}-0.153 \\
\mathrm{~A}\end{array}$ & $\begin{array}{c}0.059 \\
\mathrm{~A}\end{array}$ & 0.824 \\
\hline Factor 6 & Ball center & $\begin{array}{c}-0.173 \\
B\end{array}$ & $\begin{array}{c}0.583 \\
\mathrm{~A}\end{array}$ & $\begin{array}{c}-0.193 \\
\text { B }\end{array}$ & $\begin{array}{c}-0.197 \\
\text { B }\end{array}$ & $22.387^{* * *}$ \\
\hline Factor 7 & Toe shape & $\begin{array}{c}-0.286 \\
\mathrm{C}\end{array}$ & $\begin{array}{c}0.184 \\
\mathrm{~B}\end{array}$ & $\begin{array}{c}-0.386 \\
\mathrm{C}\end{array}$ & $\begin{array}{c}2.862 \\
\mathrm{~A}\end{array}$ & $256.035^{* * *}$ \\
\hline Factor 8 & Ball angle & $\begin{array}{c}0.278 \\
\mathrm{~A}\end{array}$ & $\begin{array}{c}-0.480 \\
\mathrm{~B}\end{array}$ & $\begin{array}{c}-0.364 \\
B\end{array}$ & $\begin{array}{c}0.051 \\
\mathrm{~A}\end{array}$ & $25.418^{* * *}$ \\
\hline
\end{tabular}

Duncan test: $\mathrm{A}>\mathrm{B}>\mathrm{C}$

${ }^{* * *} p<.001, \quad{ }^{* *} p<.01, \quad{ }^{*} p<.05$

significant difference from other types in all other items except for the height of the upper point of the heel point. In the case of factor 5 , type 1 showed smaller average measured values of the items; instep heights, heel-to-instep circumferences, and ball heights compared to those of types 3 but the values were similar to those of the remaining types. In the case of factor 6 , type 1 showed smaller average measured values of the item, ball center-to-toe 2 length(toe side length) compared to those of types 2 but the values were similar to those of the remaining types. On the other hand, type 1 showed a tendency to show higher values of the item, ball centerto-heel length compared to type 2 . In the case of factor 7 that indicates toe shapes, type 1 showed lower values of toe 5 angles compared to types 4 and the lowest values of toe 1 angles.

In the case of factor 8, type 1 showed the highest values of ball angles compared to other types. That is, types 1 has medium foot lengths which are shorter compared to those of types 2 but similar to those of other types and has the smallest ball circumferencesbreadths. It has medium ball center angles and medial ball widths(medial foot width) and relatively small instep heights, heelto-instep circumferences, and ball center-to-toe 2 lengths(toe side length). With regard to toe shapes, it has relatively low degrees of gathering of toe 1 and toe 5 toward the foot reference axis and the highest ball angles. That is, types 1 shows the normal foot shape with medium foot lengths, relatively small ball circumferences, and low degrees of gathering of toe 1 and toe 5 toward the foot reference axis.

Type 2 showed the highest scores of factor 1 that indicates foot lengths. In the case of factor 2 that indicates ball circumferences- breadths, compared to other types, type 2 showed the largest dimensions of items; ball distances, foot breadths, and ball circumferences that are all factor 2 items except for instep circumferences. In the case of factor 3 , type 2 showed the smallest ball center angles and lateral ball widths(lateral foot widths) compared to other types. In the case of factor 4 , type 2 showed larger dimensions of the heights of the upper point of the heel point compared to other types. In the case of factor 5 , type 2 showed smaller dimensions of the heel-to-instep circumferences and ball heights compared to types 3 but these dimensions were similar to those of the remaining types. In the case of factor 6 , type 2 showed the largest dimensions of the ball center-to-toe 2 lengths compared to other types while showing the smallest dimensions of the item ball center-to-heel lengths compared to other types. In the case of factor 7 that indicates toe shapes, type 2 showed smaller toe 5 angles and toe 1 angles compared to types 4 . In the case of factor 8 item ball angle, type 2 showed the smallest dimension compared to other types. This is, type 2 has the largest foot lengths and relatively large ball circumferences-breadths compared to other types. It has relatively small ball center angles, lateral ball widths(lateral foot widths), heel-to-instep circumferences, and ball heights. On the other hand, it has the largest values of the height of the upper point of the heel point compared to other types and medium degrees of gathering of toe 1 and toe 5 toward the foot reference axis. Therefore, type 2 shows the long and flat foot shape with large foot length and ball circumference-breadth values and small ball height values.

With regard to factor 1 that indicates foot lengths, types 3 
Table 9. Results of ANOVAs and posteriori tests of measured foot dimensions by foot shape type

\begin{tabular}{|c|c|c|c|c|c|c|}
\hline Factors & ${ }^{\text {Types }}$ & Type 1 & Type 2 & Type 3 & Type 4 & F-value \\
\hline \multirow{10}{*}{ Factor 1} & \multirow[t]{2}{*}{1 Foot length } & 225.61 & 230.29 & 225.14 & 226.81 & \multirow[t]{2}{*}{$9.40^{* * *}$} \\
\hline & & B & A & B & B & \\
\hline & \multirow{2}{*}{2 Heel-to-toe 1 length } & 225.42 & 229.90 & 224.69 & 226.39 & \multirow{2}{*}{$8.89^{* * *}$} \\
\hline & & B & A & B & B & \\
\hline & \multirow{2}{*}{15 Medial ball length } & 166.57 & 168.06 & 163.13 & 166.06 & \multirow{2}{*}{$7.43^{* * *}$} \\
\hline & & $\mathrm{A}$ & $\mathrm{A}$ & $\mathrm{B}$ & A & \\
\hline & \multirow{2}{*}{3 Heel-to-toe 5 length } & 184.90 & 189.28 & 185.49 & 185.39 & \multirow{2}{*}{$10.50^{* * *}$} \\
\hline & & B & A & B & B & \\
\hline & \multirow{2}{*}{16 Lateral ball length } & 143.86 & 148.42 & 142.85 & 144.94 & \multirow{2}{*}{$14.88^{* * *}$} \\
\hline & & B & A & B & B & \\
\hline \multirow{8}{*}{ Factor 2} & \multirow{2}{*}{6 Ball distance } & 90.27 & 95.13 & 93.64 & 92.36 & \multirow{2}{*}{$43.91^{* * *}$} \\
\hline & & $\mathrm{C}$ & A & B & B & \\
\hline & \multirow{2}{*}{5 Foot breadth } & 87.17 & 92.90 & 91.30 & 89.78 & \multirow{2}{*}{$72.27^{* * *}$} \\
\hline & & $\mathrm{D}$ & A & B & $\mathrm{C}$ & \\
\hline & \multirow{2}{*}{12 Ball circumference } & 228.16 & 236.94 & 240.11 & 230.81 & \multirow{2}{*}{$35.47^{* * *}$} \\
\hline & & B & A & A & B & \\
\hline & \multirow{2}{*}{13 Instep circumference } & 223.71 & 230.80 & 236.95 & 225.11 & \multirow{2}{*}{$40.48^{* * *}$} \\
\hline & & $\mathrm{C}$ & B & A & $\mathrm{C}$ & \\
\hline \multirow{6}{*}{ Factor 3} & & 1.56 & 0.955 & 3.02 & 1.82 & $8003^{* * *}$ \\
\hline & 24 Ball center angle & B & $\mathrm{C}$ & A & B & 89.03 \\
\hline & & 47.50 & 47.73 & 53.75 & 49.14 & $7585^{* * *}$ \\
\hline & 20 Lateral ball width & $\mathrm{C}$ & $\mathrm{C}$ & A & B & 15.85 \\
\hline & 19 Medial ball width & 39.69 & 45.21 & 37.60 & 40.78 & \\
\hline & 19 Medial ball width & B & A & $\mathrm{C}$ & B & 84.88 \\
\hline & 10. Heel height & 24.85 & 25.84 & 24.78 & 25.75 & \\
\hline & 10 Heer nelgnt & A & A & A & A & 3.31 \\
\hline Factor 4 & 11 Heioht of ynner noint of heel noint & 39.16 & 42.50 & 39.35 & 38.5 & $1561^{* * *}$ \\
\hline Tatur t & 11 11 & B & A & B & B & \\
\hline & 9 I ateral malleolus heioht & 63.05 & 63.62 & 62.56 & 61.42 & 213 \\
\hline & 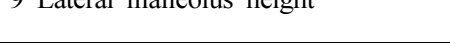 & $\mathrm{AB}$ & A & $\mathrm{AB}$ & B & 2.13 \\
\hline & 8 Insten height & 53.72 & 54.90 & 55.73 & 53.39 & $528^{* * *}$ \\
\hline & o minsep netgit & B & $\mathrm{AB}$ & A & B & 5.28 \\
\hline & 4 Hed to incten lenoth & 122.96 & 124.39 & 123.53 & 124.28 & 108 \\
\hline Factor 5 & 4 Heel-to-lnstep lengm & A & A & A & A & 1.08 \\
\hline 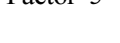 & 14 Heel-to-insten circumference & 339.44 & 346.67 & 360.96 & 338.31 & $1360^{* * *}$ \\
\hline & 14 Heel-to-instep circumierence & B & B & A & B & \\
\hline & 7 Ball heioht & 32.74 & 33.21 & 35.19 & 32.56 & $2124^{* * *}$ \\
\hline & 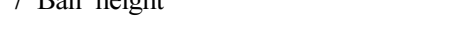 & B & B & A & B & \\
\hline & 17 Ball center-to-toe 2 lenoth & 64.80 & 73.88 & 64.71 & 65.39 & $3939^{* * *}$ \\
\hline Factor 6 & $1 /$ Dall center-to-toe 2 Iengun & B & A & B & B & 39.39 \\
\hline 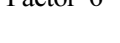 & 18 Ball center-to-heel lenoth & 157.23 & 153.37 & 157.26 & 158.28 & $445^{* * *}$ \\
\hline & to ball center-to-neer lengm & A & B & A & A & 4.45 \\
\hline & 22 Toe 5 angle & 12.11 & 13.76 & 14.94 & 40.58 & $9214^{* * *}$ \\
\hline Factor 7 & 22 loe 5 angie & B & B & B & A & 92.14 \\
\hline I actur i & 21 Toe 1 angle & 6.45 & 15.06 & 5.38 & 41.07 & $29094^{* * *}$ \\
\hline & 21 loe 1 angle & $\mathrm{C}$ & B & $\mathrm{C}$ & A & 290.94 \\
\hline Factor 8 & 23 Ball angle & 14.51 & 11.90 & 12.50 & 13.19 & $25.22^{* * *}$ \\
\hline Factor o & 25 Dall dilgie & A & $\mathrm{C}$ & $\mathrm{BC}$ & B & 23.22 \\
\hline
\end{tabular}


showed relatively smaller foot length values compared to types 2 but the values were similar to those of type 1 and type 4 . In the case of factor 2 scores, that indicates ball circumferences-breadths, type 3 showed larger ball circumference and instep circumference values compared to other types. In the case of factor 3, type 3 showed the largest ball center angle and lateral ball width values compared to other types. In the case of factor 5 , type 3 showed the largest values of the items; instep height, heel-to-instep circumferences, and ball heights. In the case of factor 6 for ball center-to-toe 2 lengths and ball center-to-heel lengths and factor 7 that indicates toe shape, type 3 tended to be similar to type 1 . That is, types 3 had medium foot lengths and the largest instep height, heel-to-instep circumferences, and ball heights compared to other types. It has relatively large ball circumference, ball center angle, and lateral ball width(lateral foot width) values. Similarly to type 1, type 3 has relatively small ball center-to-toe 2 length(toe side length) values and relatively low degrees of gathering of toe 1 and toe 5 toward the feet reference axis in toe shapes. Although type 3 shows similar tendencies to those of type 1 in foot lengths, medial-lateral ball lengths, ball center-to-toe 2 lengths, and toe shapes, it shows differences in foot shapes with relatively larger instep height and ball height values. Therefore, type 3 shows the thick foot shape with medium foot lengths, large ball circumference, instep height, and ball height values.

In the case of factor 1 that indicates foot lengths, type 4 had relatively smaller foot length values compared to types 2 but the values were shown to be similar to those of types 1 and 3 . In the case of factor 2 that indicates ball circumferences-breadths, type 4 generally showed low values and in the case of factor 3 , type 4 showed medium measured values of ball center angles, lateral ball widths, and medial ball widths. In the case of factor 5 for instep heights, heel-to-instep circumferences, and ball heights and factor 6 for ball center-to-toe 2 lengths and ball center-to-heel lengths, type 4 showed a tendency to have similar values to those of type 1 . On the other hand, in the case of factor 7 that indicates toe shape, type 4 showed the largest values of toe 5 angles and toe 1 angles compared to other types. That is, type 4 has medium foot lengths and relatively smaller ball circumferences-breadths compared to other types. It has medium values of ball center angles, lateral ball widths(lateral foot width), medial ball width(medial foot width) and relatively small values of instep heights, heel-to-instep circumferences, and ball center-to-toe 2 lengths(toe side length). It has medium ball angle values. Although type 4 has foot shapes generally similar to those of type 1 , it has high degrees of gathering of toe 1 and toe 5 toward the reference axis. Therefore, type 4 shows the toe deformation foot shape showing a difference from type 1 .

\section{Conclusion}

The purpose of the present study was to analyze differences in measured foot dimensions of middle aged and elderly women aged 40 69 years by age, classify foot shapes into multiple types, and analyze the characteristics of foot shapes by type in order to provide basic data for manufacturing of shoes for them. The results of the study are as follows.

First, when measured foot dimensions by age were compared and analyzed, higher age groups tended to have smaller foot lengths, heel-to-toe 1 lengths, heel-to-toe 5 lengths, ball circumferences, instep circumferences, ball heights, and instep heights while having larger heel height values and higher degrees of gathering of toe 1 and toe 5 toward the feet reference axis.

Second, when shoe size distributions by age were examined, foot lengths were generally shown to be in a range of $220 \mathrm{~mm} \sim 240 \mathrm{~mm}$ and ball circumference's size symbol in high frequency sections were distributed from $\mathrm{E}$ to EEEE in the 40s and 60 s groups and from D to EEEE in the 50s group.

The sections of Ball circumference's size symbol were more diversely distributed in foot lengths $230 \mathrm{~mm}$ and $235 \mathrm{~mm}$ sections in the case of the 40 s group, in foot lengths $225 \mathrm{~mm}$ and $230 \mathrm{~mm}$ sections in the case of the 50s group, and in foot lengths $220 \mathrm{~mm}$ and $225 \mathrm{~mm}$ sections in the case of the 60 s indicating that these distributions should be reflected when the last of shoes are manufactured.

Third, eight factors were extracted through factor analyses of their foot measurement items and the extracted factors explained $83.43 \%$ of the entire variance. The eight factors are length, circumference-breadth, medial-lateral balls, heel height, instep, ball center, toe shape, and ball angle.

Fourth, the subjects were classified into four types through cluster analyses and showed the following distribution; type 1; $340(57.5 \%)$, type $2 ; 135(22.8 \%)$, type $3 ; 80(13.5 \%)$, and type 4 ; $36(6.1 \%)$. Type 1 is a normal foot type with medium foot lengths and the smallest ball circumferences-breadths compared to other types. This type has relatively small instep heights and heel-toinstep circumferences, low degrees of gathering of toe 1 and toe 5 toward to foot reference axis, and the largest ball angle. Types 2 has the largest foot lengths. It has relatively large ball circumferencesbreadths but shows flat elliptical flattening with small heel-toinstep circumferences and ball heights. It has medium degrees of gathering of toe 1 toward the foot reference axis. Types 2 shows long and flat foot shape with large foot length and ball circumference-breadth values and small ball heights.

Type 3 has medium foot lengths. It has medium foot breadths 
and large ball circumferences and comprises thick feet showing round flattening with large instep height, heel-to-instep circumference, and ball height values. In addition, it has relatively low degrees of gathering of toe 1 and toe 5 toward the foot reference axis. Types 4 has medium foot lengths and relatively small ball circumferences-breadths. It has relatively small instep heights and heel-to-instep circumferences but the highest degrees of gathering of toe 1 and toe 5 toward the foot reference axis. Although type 4 has foot shapes generally similar to those of type 1 , it has high degrees of gathering of toe 1 and toe 5 toward the reference axis thereby showing a difference from type 1 with deformation of toe shapes.

As shown by the results described above, middle aged and elderly women's foot shapes can be divided into diverse types according to factors such as instep heights, ball heights, and toe 1 and toe 5 angles that indicate toe shapes in addition to items such as foot lengths and ball circumferences-breadths.

These study results are considered meaningful as basic data for shoe designs considering the characteristics of foot shapes by type of middle aged and elderly adult female consumers. In addition, the study results are also meaningful as a study regarding the analysis of foot shapes for shoe designs for middle aged and elderly adult consumers aged between 40 years and 69 years that are age groups with increasing economic influence and growing consumer markets. Since the present study analyzed middle aged and elderly adults female regionally limited to the capital region, care must be used in generalization. Therefore follow-up studies should apply the results of analysis of the characteristics of foot shape by type of middle aged and elderly adult females in wider regions to last and shoe designs.

\section{Acknowledgements}

This research was supported by the Sookmyung Women's University research grants(Project No. 1-1409-0006).

\section{References}

Choi, K., Ko, M. K., \& Chung, S. J. (2011). Middle aged women's buying behavior according to their lifestyles. Journal of the Korean Society of Clothing and Textiles, 35(4), 385-395.

Chun, J. S., \& Choi, S. H. (1999). A study on foot shape of women in Korea. Journal of the Ergonomics Society of Korea, 18(1), 109120.

Chung, S. J. (2013). Effects of self-esteem and body satisfaction of middle-aged women on their clothing satisfaction and clothing selection criteria. Fashion \& Textile Research Journal, 15(1), 8494. doi:10.5805/SFTI.2013.15.1.084

Kim, G. B. (2011). A study on the elderly women's clothing purchasing behavior according to their lifestyle. Unpublished master's thesis, Sookmyung Women's University, Seoul.

Kim, N. S., \& Do, W. H. (2014). Classification of elderly women's foot type. Journal of the Korean Society of Clothing and Textiles, 38(3), 305-320. doi:10.5850/JKSCT.2014.38.3.305

Korean Agency for Technology and Standards. (2012). 3D body shape measurement project report of middle aged and elderly persons. Retrieved June 1, 2015, from http://sizekorea.kats.go.kr/02_data/ outline.asp

Lee, J. E., \& Do, W. H. (2013). Classification of sloe types for female high school students by 2D scan data. Fashion \& Textile Research Journal, 15(6), 977-984. doi:10.5805/SFTI.2013.15.6.977

Lim, J. Y. (2007). Analysis of foot characteristics according to the classification of foot types of junior high school girls. Fashion \& Textile Research Journal, 9(3), 319-326.

Park, J. K., \& Nam, Y. J. (2004). Characteristics of elderly women's foot shape compared with young women. Journal of the Korean Society of Clothing and Textiles, 28(11), 1495-1506.

Park, J. E. (2011). Classification of adult women's foot shape and their morphological characteristics by age - By using $3 D$ foot data of Size Korea-. Unpublished doctoral dissertation, Kyung Hee University, Seoul.

Park, S. J., \& Chae, H. S. (2008). Analysis on foot measurements of elderly women for ergonomics shoes design. Fashion \& Textile Research Journal, 10(1), 83-91.

Suh, C. Y., \& Suk, E. Y. (2003). A study on foot shape of women. Journal of the Korean Home Economics Association, 41(6), 1-12.

(Received 19 August 2015; 1st Revised 6 September 2015; 2nd Revised 1 October 2015; 3rd Revised 3 October 2015; Accepted 6 October 2015)

(C) 2015 (by) the authors. This article is an open access article distributed under the terms and conditions of the Creative Commons Attribution license (http://creativecommons.org/licenses/by/3.0/), which permits unrestricted use, distribution, and reproduction in any medium, provided the original work is properly cited. 